\title{
Quantification of VEGF mRNA Expression in Non-Small Cell Lung Cancer Using a Real-Time Quantitative Reverse Transcription-PCR Assay and a Comparison with Quantitative Competitive Reverse Transcription-PCR
}

\author{
Ang Yuan, Chong-Jen Yu, Kwen-Tay Luh, Wen-Jone Chen, Fang-Yue Lin, \\ Sow-Hsong Kuo, and Pan-Chyr Yang
}

Division of Chest Medicine (AY, PCY, CJY), Department of Internal Medicine; Division of Cardiovascular Medicine (WJC), Department of Internal Medicine; Division of Cardiovascular Surgery (FYL), Department of Surgery; and Department of Laboratory Medicine (SHK, KTL), National Taiwan University Hospital, Taiwan

SUMMARY: A reliable quantitative method for measuring gene product expression is important in investigating the relationship between growth factors and tumor biological behavior. In this study, we quantified the expression of vascular endothelial growth factor (VEGF) mRNA in 104 paired samples of lung cancer tissue and the surrounding nontumorous lung tissue using a new kinetic quantitative polymerase chain reaction (PCR) method, ie, real-time quantitative reverse transcription-PCR (RTQ RT-PCR). The samples consisted of 46 squamous cell carcinomas, 50 adenocarcinomas, and 8 undifferentiated cell carcinomas. In 17 cases, the results obtained were compared with those obtained using quantitative competitive RT-PCR (QC RT-PCR). Using RTQ RT-PCR, VEGF mRNA expression was detected and quantified in all 104 (100\%) lung cancer samples and their normal counterparts. VEGF mRNA expression in the lung cancer tissue was significantly higher than in the normal counterparts $(95 \% \mathrm{Cl}$ : $0.575 \sim 1.727, p<0.001$; paired $t$ test). In 68 (65.4\%) cases, VEGF mRNA expression was higher in the cancer tissue than normal tissue. VEGF mRNA expression was higher in nonsquamous cell carcinoma $(p=0.02)$, and higher in tumor with hilar or mediastinal lymph node metastasis $(p=0.024)$. QC RT-PCR was able to detect and quantify VEGF mRNA expression in 15/17 (88\%) lung cancer samples and 12/17 (70.6\%) normal tissue samples. The values for VEGF mRNA expression were higher in the tumor in $13(76 \%)$ cases. Comparison of the values of the VEGF mRNA expression quantified using RTQ RT-PCR or QC RT-PCR showed a good correlation between results obtained using these two methods, both in cancer tissue $(r=0.68, p=0.0025)$ and normal counterpart $(r=0.53, p=0.027)$. Agreement between the results for the relative expression of VEGF mRNA expression in cancer and normal tissue obtained using these two methods was seen in 14/16 cases (88\%). We conclude that RTQ RT-PCR is as accurate as QC RT-PCR and is more sensitive than QC RT-PCR in detecting and quantifying VEGF mRNA expression in lung cancer and normal tissues, and both methods reveal that the VEGF mRNA expression is higher in lung cancer tissue than in healthy lung tissue. (Lab Invest 2000, 80:1671-1680).

$\prod$ umor angiogenesis is important in tumor growth have been shown to associate with tumor progression in several types of human cancers, such as brain, breast, gastric, renal, and lung cancers (Folkman et al, 1971; Horak et al, 1992; Macchiarini et al, 1992; Srivasta et al, 1988; Weidner et al, 1991). Several angiogenic factors are involved in the process of tumor-associated angiogenesis (Weiner, 1995). Vascular endothelial growth factor (VEGF) is known to be one of the most important angiogenic factor in various physiologic and pathologic conditions (Berkman et al, 1993; Brown et al, 1993, 1995; Suzuki et al, 1996;

Received June 19, 2000.

Address reprint requests to: Dr. Pan-Chyr Yang, National Taiwan University Hospital, No. 7, Chung-Shan South Road, Taipei 100, Taiwan. Fax: 88622322 3150; E-mail: pcyang@ha.mc.ntu.edu.tw
Takahashi et al, 1995). Assessment of the overexpression of the VEGF gene product in cells or tissue is important in studying the role of VEGF in the angiogenesis process.

Several methods for measuring VEGF expression in tissues or cells have been reported. At the protein level, immunohistochemical staining (IHC) has been used for semiquantitative analysis of VEGF expression (Fontanini et al, 1997) and ELISA has been used to quantify cytosolic VEGF protein expression (Chen et al, 1999). At the transcriptional level, Northern blots and polymerase chain reaction (PCR)-based quantitative methods have been used to assess VEGF mRNA expression in tissues (Gu et al, 1999). PCR-based quantification methods have proved to be powerful tools for the quantitative analysis of the copy number of a given target gene or mRNA, especially when only a limited amount of tissue is available, as in a small 
early-stage tumor or an aspiration biopsy specimen (Clementi et al, 1993; Ferre, 1992). Quantitative reverse transcription-PCR (RT-PCR) is conventionally performed by evaluating the amount of product after a given number of cycles (end-point quantitative PCR) (Ohta et al, 1996). Recently, quantitative competitive RT-PCR (QC RT-PCR), in which an internal DNA competitor competes with the sample cDNA for coamplification by the same primers, has been developed and shown to be a more accurate method for the quantification of cDNA (Doldrini et al, 1999; Piatak et al, 1993; Raeymaekers, 1995).

A novel approach of quantitative polymerase chain reaction using real-time detection has been developed recently, that is, real-time quantitative RT-PCR (RTQ RT-PCR) (Heid et al, 1996). RTQ RT-PCR uses the $5^{\prime}$ nuclease activity of Taq polymerase to cleave a duallabeled fluorogenic hybridization probe during the extension phase of PCR (Holland et al, 1991), the fluorescence released after cleavage being used to quantify the nucleic acid in the samples (Gibson et al, 1996). It is reported to be able to detect low-level gene amplification (myc, ccnd1, and erb B2) in breast cancer tissue (Ivan et al, 1998) and to quantify tumor necrosis factor- $\alpha$ (TNF- $\alpha$ ) mRNA expression in laserassisting picked alveolar macrophages after lipopolysaccharide (LPS) stimulation (Fink et al, 1998). The use of RTQ RT-PCR to quantify VEGF mRNA expression has not been previously reported. In the present study, we used this method to assess VEGF mRNA expression in matched tumor and healthy lung tissue samples from 104 patients with non-small cell lung cancer (NSCLC). The purposes of this study were (a) to evaluate the levels of expression of VEGF mRNA in lung cancer tissue and the surrounding healthy tissue, and (b) to compare the sensitivity and accuracy of RTQ RT-PCR with those of QC RT-PCR in the quantification of VEGF mRNA.

\section{Results}

\section{Validation of the Standard Curve and Dynamic Range of} Real-Time Quantitative RT-PCR

The standard curve was constructed using serial dilutions of RT-PCR products of the standard sample containing $500,100,50$, or 5 ng of product. Figure 1 shows the RTQ RT-PCR standard curve for VEGF mRNA. The regression coefficient for the regression line plotting the threshold cycle $\left(\mathrm{C}_{\mathrm{T}}\right)$ against the starting amount of the standard sample ranged from 0.997 to 1.000. The intra-assay and inter-assay coefficients of variation were $6.5 \%$ and $7.9 \%$, respectively. The design of the primers and the thermocycling conditions ensured that no genomic DNA was amplified and detected during this reaction (data not shown).

\section{VEGF mRNA Expression in Lung Cancer and Healthy Lung Tissue Assessed by RTQ RT-PCR}

The VEGF mRNA expression ratio (amount of VEGF mRNA/amount of $\beta$-actin mRNA) is expressed as $-\Delta \mathrm{C}_{\mathrm{T}}=-\left(\mathrm{C}_{\mathrm{T} \text { VEGF }}-\mathrm{C}_{\mathrm{T} \beta \text {-actin }}\right)$. The $-\Delta \mathrm{C}_{\mathrm{T}}$ values for
VEGF in 104 samples of lung cancer tissue ranged from 2.45 to 14.8 , with a mean \pm standard deviation (SD) of $9.7 \pm 2.34$, while the corresponding values in the matched nontumorous lung tissue ranged from 1.0 to 13.88 , with a mean \pm SD of $8.58 \pm 2.23$. VEGF mRNA expression in lung cancer tissue was significantly higher than in the matched nontumorous lung tissue (95\% Cl: 0.575 1.727, $p<0.001$, paired $t$ test) (Table 1). VEGF mRNA expression was detected in all 104 (100\%) paired lung cancer and nontumorous lung tissue samples by RTQ RT-PCR, and was higher in the tumor tissue than in the nontumorous material in 68 patients (65.4\%) and lower in 36 (35.6\%).

An immunohistochemical study of VEGF expression was performed on 72 samples of lung cancer and nontumorous lung tissue. Staining for VEGF was mainly located in the cancer cell cytoplasm in tumor tissue (Fig. 2A), whereas, in the nontumorous lung tissue, the bronchial epithelium showed positive staining (Fig. 2B). The percentage of tumor tissue that showed positive VEGF protein immunohistochemical staining ranged from $10 \%$ to $100 \%$, with mean \pm standard deviation as $79.2 \% \pm 27.2 \%$. When we correlated the percentage of tumor tissue that showed positive VEGF protein expression with VEGF mRNA quantified by RTQ RT-PCR, we found that there was a good correlation $(r=0.36953, p=0.0034$, linear regression) between the VEGF mRNA expression and VEGF protein expression in the tumors.

\section{Relationship between VEGF mRNA Expression and Clinicopathologic Variables}

Table 1 shows the relationship between VEGF mRNA expression and the clinicopathologic characteristics. VEGF mRNA expression was higher in nonsquamous cell carcinoma than in squamous cell carcinoma $(-\Delta \mathrm{CT}=10.28 \pm 2.26$ vs $9.26 \pm 2.12 ; p=0.02$, independent $t$ test) and was higher in tumors with hilar and/or mediastinal metastasis (N2-3) than without (N0-1: no lymph node metastasis or only regional lymph node metastasis) (10.38 \pm 2.07 vs $9.39 \pm 2.27$; $p=0.024$, independent $t$ test). The relationship between VEGF mRNA expression and age, sex, stage, or tumor status was not statistically significant.

\section{Quantification of VEGF mRNA Expression Using QC RT-PCR}

Seventeen paired lung cancer and nontumorous tissue samples were randomly selected for quantification of VEGF mRNA expression using QC RT-PCR. Examples of the QC RT-PCR for VEGF and G $\beta$-like cDNA are shown in Figure 3, A and B. The ethidium bromidestained electrophoresis gel showed competition between the PCR products of the native RNA and the serial dilutions of internal competitor RNA for both the VEGF and $G$-like genes. Linear regression was used to calculate the amount of VEGF cDNA (Fig. 3C). Since the starting amounts of native VEGF cDNA and internal competitor are equal when the ratio of their PCR products is 1 ( $\log$ ratio $=0$ ), the amount of native 

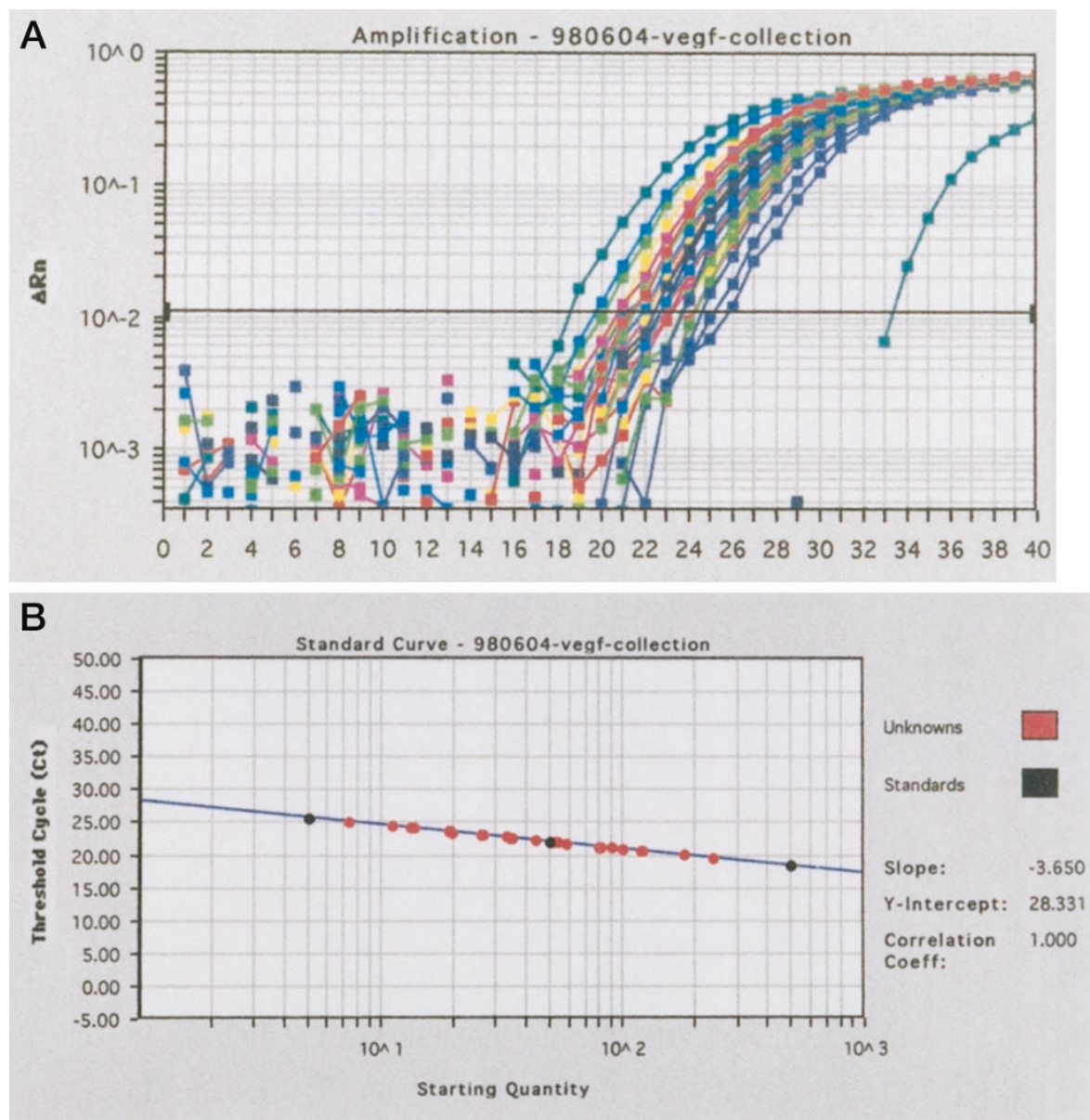

\section{Figure 1.}

Quantification of VEGF mRNA in lung cancer tissue using real-time quantitative RT-PCR. $A$, Amplification plots for reactions involving the four points of the VEGF mRNA standard control, tissue sample mRNA, and nontemplate control. Cycle number is plotted versus change in the normalized reporter signal $(\Delta R n)$. For each reaction, the fluorescence signal of the reporter dye (FAM) is divided by the fluorescence signal of the passive reference dye (ROX) to obtain a ratio defined as the normalized reported signal (Rn). $\Delta R n$ represents the normalized reporter signal $(\mathrm{Rn})$ minus the baseline signal. $\Delta R n$ increases during PCR as the VEGF mRNA RT-PCR product increases until the reaction reaches a plateau. The threshold cycle $\left(\mathrm{C}_{\mathrm{T}}\right.$ value) represents the fractional cycle number at which a significant increase in $\mathrm{Rn}$ above a chosen threshold (horizontal black line) can first be detected. $B$, Standard curve of $\mathrm{C}_{\mathrm{T}}$ value vs log starting quantity of VEGF mRNA. The black dots represent the data for the standard samples and the red dots those for unknown tissue samples.

VEGF mRNA can be calculated from the amount of internal competitor at the point where the regression line intersects the $x$ axis. The regression coefficient for the linear regression line in the QC RT-PCR assay ranged from -0.948 to -1.000 and the intra-assay and inter-assay coefficients of variation were $10.4 \%$ and $16.8 \%$, respectively.

The VEGF mRNA/housekeeping gene ( $\mathrm{G} \beta$-like) expression ratio in cancerous and nontumorous lung tissue are shown in Table 2. In lung cancer material, this ranged from 0 to 944 , with a mean \pm SD of 109.9 \pm 237.6, whereas in the nontumorous material, it ranged from 0 to 87.3 , with a mean \pm SD of $23.1 \pm$ 32.3. VEGF mRNA expression in lung cancer tissue was higher than in nontumorous lung tissue, although the difference was not statistically significant $(95 \% \mathrm{Cl}$ : -36.1 to 209.6; $p=0.153$, paired $t$ test).

VEGF mRNA expression was detected in 15/17 (88\%) samples of lung cancer tissue and in 12/17 (70.6\%) samples of nontumorous lung tissue. VEGF mRNA was not detected by QC RT-PCR in 7/34 (20.6\%) samples. The VEGF mRNA expression ratio was higher in lung cancer tissue than in nontumorous material in $13(76.4 \%)$ patients and lower in $3(17.6 \%)$. In one patient, no VEGF mRNA was detected by QC RT-PCR in either the lung cancer sample or nontumorous sample. Expression of the house-keeping gene $G$ $\beta$-like mRNA was detected in all samples of cancerous and nontumorous lung tissue.

\section{Comparison of VEGF mRNA Expression Detected by RTQ RT-PCR and QC RT-PCR}

We compared the VEGF mRNA expression ratios determined by RTQ RT-PCR or QC RT-PCR in 17 paired lung cancer and nontumorous samples (Table 2). A good correlation was seen between the values for VEGF mRNA determined by RTQ RT-PCR or QC RT-PCR in both lung cancer tissue $(r=0.68, p=$ $0.0025)$ and nontumorous lung tissue $(r=0.53, p=$ $0.027)$. The $-\Delta$ CT value for VEGF mRNA was higher in lung cancer tissue than in the nontumorous tissue in $12(71 \%)$ patients and lower in 5 (29\%). The VEGF mRNA expression ratio assessed by QC RT-PCR was 
Table 1. Relationship between VEGF mRNA Expression and Clinicopathologic Characteristics

\begin{tabular}{|c|c|c|c|}
\hline Variables & No. & $\begin{array}{l}\text { VEGF mRNA } \\
\text { expression } \\
\text { (mean } \pm \mathrm{sD})\end{array}$ & $P$ value \\
\hline \multicolumn{4}{|l|}{ Sex } \\
\hline Male & 68 & $9.78 \pm 2.28$ & \multirow[t]{2}{*}{0.914} \\
\hline Female & 36 & $9.83 \pm 2.21$ & \\
\hline \multicolumn{4}{|l|}{ Histologic type } \\
\hline Squamous & 46 & $9.26 \pm 2.12$ & \multirow[t]{2}{*}{0.02} \\
\hline Nonsquamous & 58 & $10.28 \pm 2.26$ & \\
\hline \multicolumn{4}{|l|}{ Stage } \\
\hline$|-| \mid$ & 56 & $9.43 \pm 2.12$ & \multirow[t]{2}{*}{0.137} \\
\hline III-IV & 48 & $10.10 \pm 2.32$ & \\
\hline \multicolumn{4}{|l|}{ Tumor status } \\
\hline $\mathrm{T} 1$ & 23 & $9.59 \pm 2.47$ & \multirow[t]{2}{*}{0.65} \\
\hline T2-4 & 81 & $9.85 \pm 2.18$ & \\
\hline \multicolumn{4}{|l|}{ Lymph node status } \\
\hline No-1 & 62 & $9.39 \pm 2.27$ & \multirow[t]{2}{*}{0.024} \\
\hline N2-3 & 42 & $10.38 \pm 2.07$ & \\
\hline \multicolumn{4}{|l|}{ Tissue } \\
\hline Tumor & 104 & $9.7 \pm 2.34$ & \multirow[t]{2}{*}{$0.001^{*}$} \\
\hline Nontumorous & 104 & $8.58 \pm 2.23$ & \\
\hline $\begin{array}{l}\text { VEGF, vascular endoth } \\
\text { polymerase chain reactior } \\
{ }^{a} \text { VEGF mRNA expres } \\
-\left(\mathrm{C}_{\mathrm{T} \text { VEGF }}-\mathrm{C}_{\mathrm{T}_{\beta} \text {-actin }}\right) . \\
{ }^{*} p \text { value derived from }\end{array}$ & $\begin{array}{l}\text { owth fo } \\
\text { reshol }\end{array}$ & $\begin{array}{l}\text { or; RT-PCR, reverse } \\
\text { ycle. } \\
\text { m real-time quantit }\end{array}$ & $\begin{array}{l}\text { ranscription } \\
\text { ive } R T-P C R\end{array}$ \\
\hline
\end{tabular}

higher in lung cancer tissue than in nontumorous material in 13 (76.4\%) patients and lower in 3 (17.6\%), and for one patient, there was no VEGF mRNA detected in either tissue sample. A good agreement between these two quantitative PCR methods in terms of the relative amounts of VEGF mRNA expression in lung cancer and nontumorous tissues was seen in $14 / 16$ patients (88\%). For one patient, the relationship could not be determined because VEGF mRNA was not detected by QC RT-PCR in either sample.

\section{Discussion}

Angiogenesis is important in the growth and progression of solid tumors and is a critical step in the process of systemic metastasis (Schor and Schor, 1983). Recently it has been reported to be associated with an increased incidence of metastasis and a worse prognosis in cancers of several organs, eg, gastric, breast, renal, and primary lung cancers (Folkman et al, 1971; Horak et al, 1992; Macchiarini et al, 1992; Srivasta et al, 1988; Weidner et al, 1991). VEGF is one of the most important angiogenic factors and is an endothelial cell-specific mitogen. It is therefore important to be able to assess VEGF gene product expression in tumor cells in order to understand the role of VEGF in tumor angiogenesis and in the biological behavior of tumors. Many studies of VEGF expression in various malignancies have been performed in recent years (Berkman et al, 1993; Boocock et, 1995; Fontanini et al, 1997; Ohta et al, 1996, 1997; Oshika et al, 1994;

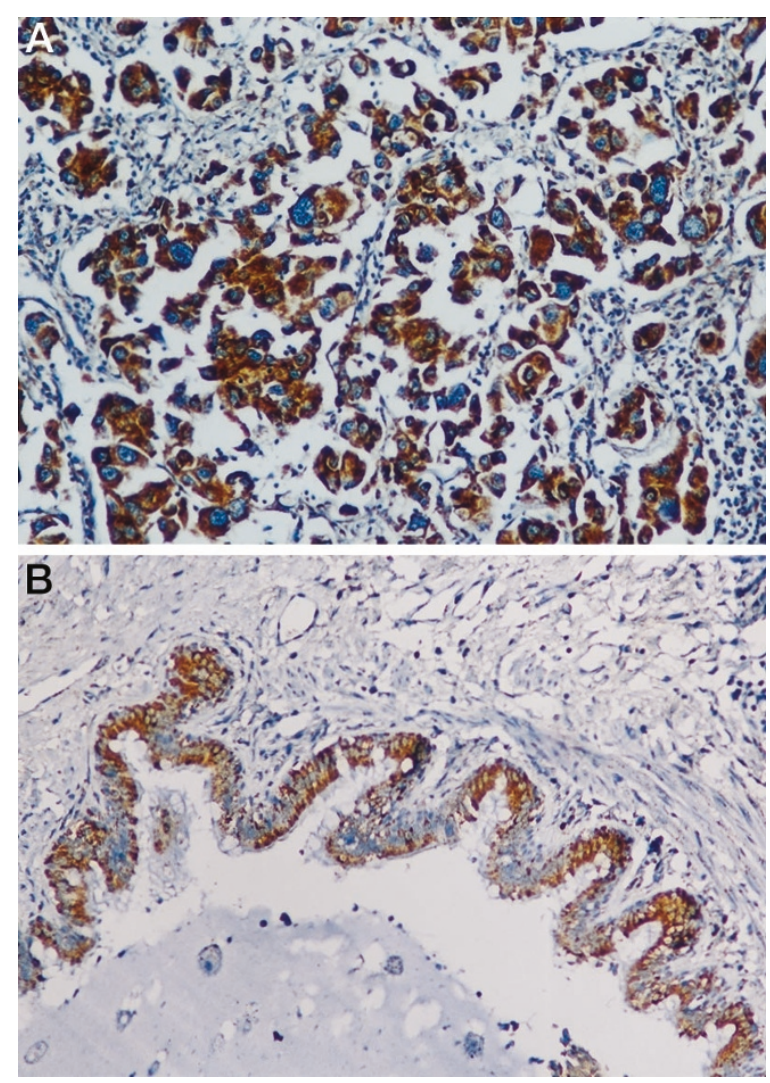

\section{Figure 2.}

Immunohistochemical staining of VEGF protein in adenocarcinoma $(A)$ and $(B)$ in normal bronchial epithelium (avidin-biotin peroxidase complex method, $\times 400$ magnification). The brown color indicates VEGF protein expression, which was located mainly in the cytoplasm of the cancer cells in tumor tissue and in epithelial cells of normal bronchus.

Suzuki et al, 1996; Tokunaga et al, 1998; Viglietto et al, 1996).

Gene product expression has been mainly studied by assessment of mRNA or protein expression. Northern blotting has been used to assess mRNA expression, but it is not sensitive enough and requires relatively large amounts of high-quality total RNA (5-10 $\mu \mathrm{g} /$ reaction). PCR has recently been used to amplify the target cDNA and to determine the amount of a specific mRNA from a minimal amount of a tissue sample or a small number of cells. Several PCR-based methods have been developed to quantify mRNA overexpression in tumors. The conventional quantitative RT-PCR assay measures the end product of PCR amplification after a given number of cycles (end-point quantitative RT-PCR). An internal control mRNA (housekeeping gene) is required to determine PCR efficiency. In addition, for effective quantification, the reaction must be stopped before amplification reaches the plateau phase (oversaturation) (Kellogg et al, 1990), so serial dilutions of the sample must be employed to ensure that the linear part of the curve is used. Despite these problems, it is currently the most frequently used method.

QC RT-PCR, recently developed and now widely used for PCR quantification, relies on the coamplification of the target mRNA with an internal 
(A) VEGF

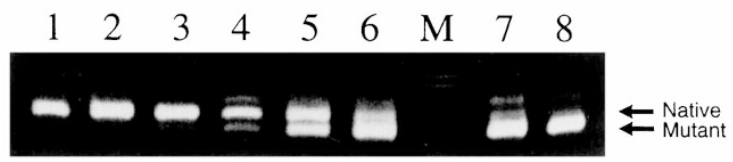

(B) $G \beta$-like

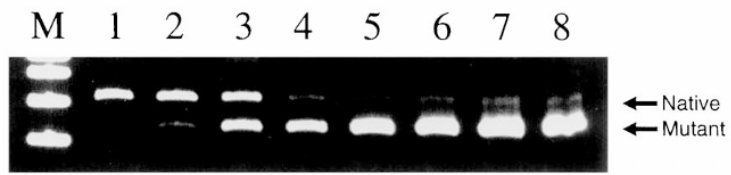

(C)

VEGF

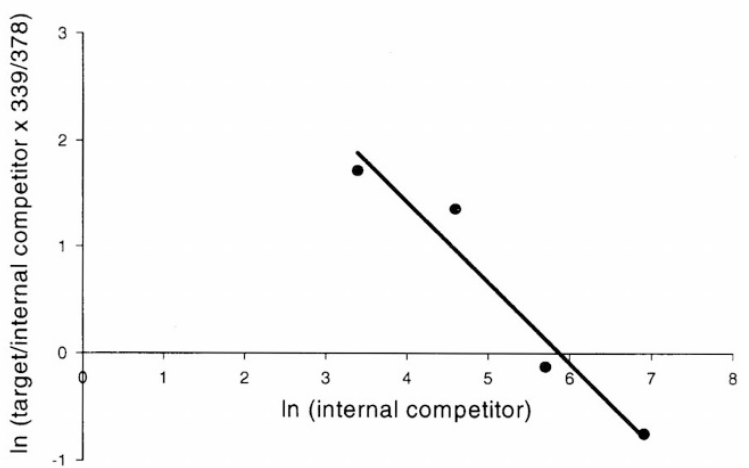

Figure 3.

Examples of the QC RT-PCR products of native and mutant (internal competitor) VEGF $(A)$ and $\mathrm{G} \beta$-like mRNA $(B)$ after electrophoresis in a $6 \%$ nondenaturing polyacrylamide gel and staining with ethidium bromide. Lanes 1 to 8 in $A$ represent the QC RT-PCR products of the sample RNA and serial dilutions (1000, 300, 100, $30,10,3,1$, or $0.3 \mathrm{pg}$ ) of the internal competitor for VEGF mRNA. Lanes 1 to 8 in $B$ represent the QC RT-PCR reaction for the G $\beta$-like mRNA (housekeeping gene) as internal control. M represents the 100 bp DNA marker. Competition occurs between the native and mutant target genes in the PCR reaction. $C$, An example of linear regression used to calculate the amount of VEGF gene transcripts in a tumor specimen. The linear regression equation was $y=a+b x$, where the values on the $y$ axis are natural log transformations (intensity of native fragment $\times$ size of internal competitor/intensity of internal competitor $\times$ size of native fragment) and the values on the $x$ axis are natural log transformations of the amount of internal competitor in each tube of the PCR reaction. The amount of native VEGF mRNA was calculated from the value of the internal competitor at the point of intersection of the regression line and the $x$ axis.

Table 2. Quantitation of VEGF mRNA in Lung Cancer and Healthy Lung Tissue Using Real-Time Quantitative RT-PCR and QC RT-PCR

\begin{tabular}{|c|c|c|c|c|c|c|}
\hline \multirow[b]{2}{*}{ No. } & \multicolumn{3}{|c|}{ Real-time RT-PCR: $-\left(\mathrm{C}_{\mathrm{T} \text { VEGF }}-\mathrm{C}_{\mathrm{T} \beta \text {-actin }}\right)$} & \multicolumn{3}{|c|}{ QC RT-PCR (VEGF/G $\beta$ ) } \\
\hline & Tumor & Healthy & Tumor vs healthy & Tumor & Healthy & Tumor vs healthy \\
\hline 1 & 8.5 & 6.2 & $>$ & 20 & 0.81 & $>$ \\
\hline 2 & 8.5 & 6 & $>$ & 17.1 & 0.72 & $>$ \\
\hline 3 & 7 & 7.84 & $<$ & 5.42 & 2.56 & $>$ \\
\hline 4 & 6.5 & 8.55 & $<$ & 0 & 35.3 & $<$ \\
\hline 5 & 7.87 & 7.56 & $>$ & 1.55 & 0 & $>$ \\
\hline 6 & 6.05 & 5 & $>$ & 0 & 0 & ND \\
\hline 7 & 8 & 7.1 & $>$ & 1.89 & 0 & $>$ \\
\hline 8 & 14.8 & 8 & $>$ & 944 & 6.44 & $>$ \\
\hline 9 & 11.84 & 10.76 & $>$ & 72.3 & 30.9 & $>$ \\
\hline 10 & 9.54 & 10.39 & $<$ & 60.64 & 26.5 & $>$ \\
\hline 11 & 10.25 & 10.76 & $<$ & 28 & 85.2 & $<$ \\
\hline 12 & 11.34 & 11.44 & $<$ & 55.64 & 59.05 & $<$ \\
\hline 13 & 14.6 & 11.16 & $>$ & 302.1 & 4.12 & $>$ \\
\hline 14 & 10.89 & 7.39 & $>$ & 336.8 & 87.3 & $>$ \\
\hline 15 & 9.52 & 5.4 & $>$ & 60 & 12.39 & $>$ \\
\hline 16 & 3.84 & 3.74 & $>$ & 2.92 & 0 & $>$ \\
\hline 17 & 7.6 & 6.8 & $>$ & 1.24 & 0 & $>$ \\
\hline
\end{tabular}

QC RT-PCR, quantitative competitive RT-PCR; $>$ VEGF mRNA in cancer tissue greater than in healthy tissue; $<$ VEGF mRNA in cancer tissue less than in healthy tissue; ND, not detected.

competitor. Serial dilutions of a known concentration of internal competitor are added to the sample. For relative quantification, the unknown target PCR products are compared with the known competitor PCR products. The starting amount of target cDNA is assumed to be equal to the starting amount of internal competitor when the amounts of their PCR products are equal. The aims of this competitive approach are to circumvent the problems of the different annealing efficiencies of different primer sets and provide a more accurate standard for quantification of nucleic acid. The success of a quantitative competitive PCR assay relies on developing an internal competitor that amplifies with the same efficiency as the target molecule. The internal competitor can be designed using a homologous or nonhomologous DNA fragment that contains the same primer templates as the target cDNA. Because of its accuracy in quantification, QC RT-PCR is being increasingly used to quantify mRNA expression (Doldrini et al, 1999; Piatak et al, 1993; Raeymaekers, 1995).

In this study, we used RTQ RT-PCR to quantify VEGF mRNA expression in 104 (100\%) lung cancer samples. The characteristics of this method are that it 
quantifies the PCR product when PCR amplification is still in the exponential phase (kinetic quantitative PCR), rather than the PCR end product (Gibson et al, 1996; Heid et al, 1996; Holland et al, 1991; Ivan et al, 1998), and it has been shown to be a more reliable method for quantifying the starting copy number of target molecules than the end product method. The results were positive in all 104 (100\%) lung cancer and nontumorous healthy tissue samples. For comparison, QC RT-PCR was performed on 17 paired samples and was able to detect VEGF mRNA expression in 15/17 $(88 \%)$ lung cancer samples and 12/17 (76\%) nontumorous samples. Higher VEGF mRNA expression by the tumor was seen in 13 cases $(76 \%)$ by QC RT-PCR compared with 12 cases $(71 \%)$ by RTQ RT-PCR. There was a good correlation between the values for VEGF mRNA expression obtained using the two methods $(p<0.05)$. There was also a good agreement between the two methods in terms of determining relative VEGF mRNA expression in the lung cancer and nontumorous lung tissue in 14 paired tissue samples. The results showed that RTQ RT-PCR is as accurate as QC RT-PCR in quantifying VEGF mRNA in tumor and healthy tissue.

Ohta et al (1996) assessed VEGF mRNA expression in primary lung cancer using the conventional quantitative RT-PCR method and detected VEGF mRNA in $29 / 42$ (71\%) samples of cancer tissue. Doldrini et al (1999) reported the use of QC RT-PCR to quantify VEGF mRNA expression in cancer and normal tissue samples from 22 patients with non-small cell lung cancer (NSCLC), all of which were known to be positive for VEGF expression by qualitative RT-PCR. They detected VEGF mRNA in 18 samples of healthy tissue and in all samples of tumor tissue and found VEGF expression to be higher in the tumor than in the matched healthy tissue in 17 cases. However, using QC RT-PCR, no VEGF PCR product was detected in $4 / 22(18.4 \%)$ samples of healthy lung tissue, although all these healthy tissue samples were positive for VEGF mRNA expression assessed by qualitative RTPCR. These results showed that, despite the advantage of accuracy in quantification, QC RT-PCR was no more sensitive than conventional RT-PCR in detecting VEGF mRNA in tissues, the overall sensitivity being about $91 \%$ in this series. Further serial dilution of the internal competitor may be required to measure tiny amounts of VEGF mRNA in normal tissue.

In our study, when QC RT-PCR was performed on 17 pairs of lung cancer and nontumorous lung tissue samples, VEGF mRNA expression was detected and quantified in $15 / 17$ (88\%) samples of lung cancer tissue and in 12/17 (76\%) samples of nontumorous lung tissue, the overall sensitivity being around $79.4 \%$. In contrast, RTQ RT-PCR was able to detect and quantify VEGF mRNA expression in all 104 (100\%) paired samples in our study. Furthermore, the starting amount of total RNA used for RTQ RT-PCR was $50 \mathrm{ng}$, much lower than the amount $(6 \mu \mathrm{g})$ required for $\mathrm{QC}$ RT-PCR. These results show that, in terms of detecting VEGF mRNA expression, RTQ RT-PCR is the most sensitive of these three PCR-based quantitative meth- ods. The high sensitivity of this method may be due to its wide dynamic range for quantification and the sensitivity of the fluorescence method used during the process of PCR amplification (Ivan et al, 1998).

RTQ RT-PCR has several additional advantages over other PCR-based assays. (a) It gives more precise and reproducible mRNA quantification because it is based on the $C_{T}$ value rather than end-point measurement of the amount of accumulative PCR product. (b) It has a linear dynamic range of at least four orders of magnitude. (c) It can avoid carry-over contamination of amplified product using the enzyme uracil N-glycosylase (UNG) (Longo et al, 1990). (d) Unlike QC RT-PCR, it does not require the design and storage of an internal competitor or the validation of the amplification efficiency of the internal competitor. (e) It does not require post-PCR manipulation, thus making sample analysis simple and rapid. (f) It is able to analyze large numbers of samples in one reaction (Celi et al, 1994).

VEGF mRNA has at least four isoforms (VEGF121, VEGF165, VEGF189, and VEGF206), which are derived by alternative splicing of a single gene (Dvorak et al, 1995). These four isoforms have a common sequence in exon 1-5 and exon 8 (Tokunaga et al, 1998). Using different fluorescent reporter molecules in probes that hybridize specifically with different isoforms, RTQ RT-PCR can quantify each of the four VEGF $m R N A$ isoforms in a single reaction. The quantification of nucleic acid by QC RT-PCR is based on competition between two similar cDNA templates (target DNA and competitor). However, when more than two target sequence isoforms are present, calculation of the amount of any one isoform might be difficult. This might be a further advantage of RTQ RT-PCR over QC RT-PCR, especially when multiple mRNA isoforms have to be quantified in the same sample.

We conclude that RTQ RT-PCR is as accurate as, and may be more sensitive than, QC RT-PCR in the quantification of VEGF mRNA expression in NSCLC and that RTQ RT-PCR can be used as an additional reliable method of assessing gene product expression in clinical research.

\section{Materials and Methods}

\section{Patients, Tissue Samples and RNA Extraction}

Samples were obtained from 104 primary lung carcinomas, resected surgically from patients at this institution (National Taiwan University Hospital) between 1994 and 1996. The patients consisted of 68 men and 36 women, with a mean age of $58.2 \pm 12.4$ years. The histologic classification of lung cancer was determined as recommended by the World Health Organization (WHO, 1982) and tumor staging was performed according to the TMN staging system (Mountain, 1986). The cancer specimens included 46 squamous cell carcinomas, 50 adenocarcinomas, and 8 undifferentiated carcinomas. Tumor staging was I in 36 cases, II in 20 cases, IIIA or IIIB in 47 cases, and IV in 1 case (Table 3). Immediately after surgery, the tumor sam- 
Table 3. Demographic Data of 104 Patients with Non-Small Cell Lung Cancer

\begin{tabular}{lc}
\hline \multicolumn{1}{c}{ Variables } & \\
\hline Mean age \pm SD (yr) & $58.2 \pm 12.4$ \\
Sex & 68 \\
Male & 36 \\
Female & \\
Histologic type & 46 \\
Squamous cell CA & 50 \\
Adenocarcinoma & 8 \\
Undifferentiated & \\
Stage & 36 \\
I & 20 \\
II & 47 \\
IIIA and IIIB & 1 \\
IV & \\
Tumor status & 23 \\
T1 & 51 \\
T2 & 22 \\
T3 & 8 \\
T4 & \\
Lymph node status & 38 \\
N0 & 24 \\
N1 & 32 \\
N2 & 10 \\
N3 & \\
\hline
\end{tabular}

$\mathrm{CA}$, carcinoma.

ples and surrounding healthy lung tissue were placed in liquid nitrogen and stored frozen at $-80^{\circ} \mathrm{C}$. A RNA extraction kit (Rneasy Mini Kit; Qiagen, Valencia, California) was used to extract total mRNA from the resected lung tissue.

\section{Real-Time Quantitative RT-PCR}

Theoretical Basis. This method (TaqMan reaction) is based on the $5^{\prime}$ nuclease activity of Taq polymerase, which cleaves a specific dual-labeled fluorogenic hybridization probe during the extension phase of PCR. As long as this sequence-specific probe is intact, emission by a reporter dye at its $5^{\prime}$ end is quenched by a second fluorescent dye at the $3^{\prime}$ end. During the extension phase of the PCR, Taq polymerase hydrolyzes the probe and releases the reporter dye, resulting in an increase in peak fluorescence emission that is directly proportional to the number of amplified copies and is detected and quantified by a detector in real-time. A higher starting copy number of the nuclear acid results in an earlier increase in fluorescence. The threshold cycle $\left(\mathrm{C}_{\mathrm{T}}\right)$ is defined as the fractional cycle number at which the fluorescence generated by cleavage of the probe exceeds a fixed threshold above baseline (Fig. 1, A and B). For a chosen threshold, a smaller starting copy number results in a higher $C_{T}$ value. In this study, we used RTQ RT-PCR for the relative quantification of VEGF mRNA in tumor specimens, using $\beta$-actin mRNA as an internal control.

Primers, Probes, and Reference Internal Control $m R N A$. Primers and probes were chosen using the computer program, Primer Express (Perkin-Elmer Applied Biosystems, Forster City, California). Primers and probes were synthesized and bought from PerkinElmer Applied Biosystems. Based on the cDNA sequence (Gene bank, accession No. m32977), the primers used for RTQ RT-PCR of VEGF mRNA were as follows: (a) forward primer, 5'-GCA CCC ATG GCA GAA GG-3' (in exon 2) and (b) reverse primer: 5'-CTC GAT TGG ATG GCA GTA GCT-3' (in exon 3). The sequence of the probe for detection and quantification of PCR product was as follows: 5'-ACG AAG TGG TGA AGT TCA TGG ATG TCT ATC AC-3', which was spanning the exon2 $\sim$ exon3 junction. This sequence was chosen to eliminate the quantification of PCR product of contaminated VEGF genomic DNA. $\beta$-actin mRNA (internal control) in the tumor sample was quantified in the same way, using forward and reverse primers and a probe designed for $\beta$-actin mRNA analysis. The forward primer sequence for $\beta$-actin mRNA quantification was 5'-CGC CCA GCA CGA TGA AA-3'; the reverse primer sequence was 5'-CCG CCG ATC CAC ACA GA-3'; and the probe sequence was 5'-AAG ATC ATT GCT CCT CCT GAG CGC AAG T-3'.

Standard Curve Sample Preparation. The standard curve samples used for RTQ RT-PCR were prepared by serial dilution of a specific RNA sample to cover the range of $500 \mathrm{ng}$ to $5 \mathrm{ng}$. The serially diluted samples were aliquotted and stored at $-80^{\circ} \mathrm{C}$ until use.

$R T-P C R$ Procedure. The amplification mixture (50 $\mu$ l) contained $50 \mathrm{ng}$ of sample RNA, $5 \times$ TaqMan EZ buffer $(10 \mu \mathrm{l}), 25 \mathrm{~mm}$ manganese acetate $(6 \mu \mathrm{l}), 300 \mu \mathrm{M}$ deoxyadenosine triphosphate (dATP) deoxycytidine triphosphate (dCTP), deoxyguanosine triphosphate (dGTP), and $600 \mu \mathrm{m}$ deoxyuridine triphosphate (dUTP), 5 units of $r T$ th DNA polymerase, 0.5 units of AmpErase uracil N-glycosylase (UNG), 200 nM VEGF forward and reverse primers, and 100 nM VEGF probe (PerkinElmer Applied Biosystems). The rTth DNA polymerase had both RTase and Taq polymerase activity. The thermal cycling parameters were as follows: initial step of 2 minutes at $50^{\circ} \mathrm{C}, 30$ minutes at $60^{\circ} \mathrm{C}$ for reverse transcription, 5 minutes at $95^{\circ} \mathrm{C}$ for deactivation, and then 40 cycles at $94^{\circ} \mathrm{C}$ for 20 seconds and $62^{\circ} \mathrm{C}$ for 1 minute for the melting, annealing, and extending phases of the PCR reaction. Each assay included standard curve samples in duplicate, a no-template control, and about $50 \mathrm{ng}$ of sample total RNA in triplicate. All samples with a coefficient of variation (CV) higher than $10 \%$ were retested.

Detection of Fluorescence Emission and Quantification of VEGF $m R N A$. The fluorescence emission from the reporter dye (FAM-6-carbosy-fluorescein, peak fluorescence emission at $518 \mathrm{~nm}$ ) was detected on-line using an $A B I$ prism 7700 sequence detection system (Perkin-Elmer Applied Biosystems) in real time. The amount of VEGF mRNA in the tissue, standardized to the $\beta$-actin mRNA, was expressed as $-\Delta \mathrm{C}_{\mathrm{T}}=-\left(\mathrm{C}_{\mathrm{T} \text { VEGF }}-\mathrm{C}_{\mathrm{T} \beta \text {-actin }}\right)$. The ratio of the amount of VEGF mRNAvamount of $\beta$-actin mRNA was then calculated as $2^{-\triangle C T} \times \mathrm{K}(\mathrm{K}$, constant).

Immunohistochemical Staining of VEGF. Expression of VEGF protein was assessed by immunohistochem- 
ical staining, using a modified version of the avidinbiotin peroxidase complex method (Yuan et al, 1995). The percentage of tumor tissue that showed positive VEGF staining was counted randomly on five $\times 200$ fields (Volm et al 1997).

\section{Quantitative Competitive RT-PCR}

Construction of the Competitive Fragments Used for QC RT-PCR. The competitive templates for amplification of the VEGF and $\mathrm{G} \beta$-like genes (housekeeping gene as an internal control) were complementary RNA (cRNA) fragments produced by in vitro transcription of the mutated DNA fragment constructed using the PCR technique developed by Celi and Dong (Celi et al, 1993; Dong et al, 1993). Table 4 summarizes the primer sets used for generating both mutated and native PCR fragments of the VEGF gene and G $\beta$-like gene. The mutated PCR fragments were ligated into the T7 vector and in vitro transcription was performed using T7 RNA polymerase. The details of the procedure have been published (Yu et al, 1998). The sizes of the PCR products for the mutated VEGF and G $\beta$-like DNA fragments (internal competitor) were 339 and 225 base pairs, respectively.

In Vitro Transcription of RNA Templates (Internal Competitor) for QC RT-PCR. Ten micrograms of T7 vector was cloned with each specific mutated PCR fragment. After electrophoresis on a 1\% agarose gel, the bands were extracted with phenol-chloroform and alcohol precipitated, and the material was dissolved in water treated with diethyl pyrocarbonate (DEPC- $\left.\mathrm{H}_{2} \mathrm{O}\right)$. A measured amount $(3.75 \mu \mathrm{g})$ of the material was added to $20 \mu \mathrm{l}$ of first strand reaction mixture $(200 \mathrm{~mm}$ Tris- $\mathrm{HCl}, 30 \mathrm{~mm} \mathrm{MgCl}_{2}, 10 \mathrm{~mm}$ spermicide, $10 \mathrm{~mm}$ dithiothreitol), $100 \mathrm{U}$ of RNAsin (Rnase inhibitor 400 $\mathrm{U} / \mu \mathrm{l}$; Promega, Madison, Wisconsin), nucleoside triphosphates (NTPs) (50 mм ATP, CTP, GTP, UTP), and $40 \mathrm{U}$ of T7 RNA polymerase in a total reaction volume of $100 \mu \mathrm{l}$. After incubation at $39^{\circ} \mathrm{C}$ for 2 hours, $4 U$ of Rnase-free DNase RQ-1 was added, and the mixture incubated at $37^{\circ} \mathrm{C}$ for 15 minutes to degrade the DNA template. After phenol-chloroform-isoamyl alcohol elution and alcohol precipitation, the RNA transcript was dissolved in $20 \mu$ l of DEPC- $\mathrm{H}_{2} \mathrm{O}$. After spectrophotometric measurement of the concentration, the RNA was serially diluted and stored at $-70^{\circ} \mathrm{C}$. The cRNA transcripts are referred to as the internal competitors (standards) for the VEGF and G $\beta$-like genes for the QC RT-PCR.

QC RT-PCR. Seventeen matched samples of lung cancer material and the surrounding normal tissue were randomly selected for QC RT-PCR to measure VEGF mRNA expression. The total RNA was extracted using the method described above.

Six micrograms of tissue total RNA was added to 8 $\mu \mathrm{g}$ of random primer in a final volume of $10 \mu \mathrm{l}$. A measured amount $(1.25 \mu \mathrm{l})$ of this mixture was added to each of 8 tubes containing, respectively, 1,000, 300, $100,30,10,3,1$, or $0.3 \mathrm{pg}$ of target gene RNA internal competitor. The RT reaction was carried out in a final volume of $6.25 \mu \mathrm{l}$, with the addition of a reaction mixture containing Superscript RTase (BRL, Gaithersburg, Maryland), Rnasin, dNTP, dithiothreitol, and $5 \times$ reaction buffer. After reaction at $37^{\circ} \mathrm{C}$ for 90 minutes, the RT products were diluted with $12 \mu$ l of deionized distilled water and heated at $85^{\circ} \mathrm{C}$ for 5 minutes. Two microliters of RT products from each tube were used for PCR in a volume of $20 \mu$ lincluding Tag polymerase, $\mathrm{MgCl}_{2}, 10 \times$ buffer, dNTP, and primers for VEGF or $\mathrm{G} \beta$-like gene). The thermocycle conditions for the VEGF and $G \beta$-like genes are listed in Table 4.

After amplification, the PCR products were electrophoresed at $80 \mathrm{~V}$ for 1 to 2 hours on a $6 \%$ nondenaturing polyacrylamide gel, stained with $5 \mu \mathrm{g} / \mathrm{ml}$ ethidium bromide solution for 3 minutes, and destained. The signal intensities of the amplified native and mutated products were directly measured and digitized using an Is-1000 digital imaging system (Alpha Innotech Corporation, San Leandro, California). Using quantitative densitometry, the intensities of the native and mutant VEGF gene products were plotted as a function of the known amounts of mutant templates. When the intensities of the native and mutated gene products were equal, the molecules of the native VEGF mRNA transcript were equal to those of the mutant template. The amounts of VEGF mRNA were

Table 4. Primer Sets and Thermocycle Conditions Used in Constructing the Internal Competitors of VEGF and G $\beta$-Like mRNA, and in PCR

\begin{tabular}{|c|c|c|c|c|}
\hline Gene & & Primers (nucleotide positions) & $\begin{array}{l}\text { Sizes of } \\
\text { PCR } \\
\text { products } \\
\quad(b p)\end{array}$ & Thermocycle conditions \\
\hline VEGF & $\begin{array}{l}\text { Forward } \\
\text { Reverse } \\
\text { Reverse } \\
\text { (Mutant) }\end{array}$ & $\begin{array}{l}\text { 5'-CTGCTGTCTTGGGTGCATTG }(-69 \sim-50) \\
\text { 5'-TTCACATTTGTTGTGCTGTAG }(289 \sim 309) \\
\text { 5'-TTCACATTTGTTGTGCTGTAG } \\
\text { GATCCGCATAATCTGCATGG }(230 \sim 249)\end{array}$ & $\begin{array}{l}378 \\
339\end{array}$ & $\begin{array}{l}94^{\circ} \mathrm{C} 5 \mathrm{~min} \text { for } 1 \text { cycle, }\left(94^{\circ} \mathrm{C} 1 \mathrm{~min},\right. \\
\left.53^{\circ} \mathrm{C} 2 \mathrm{~min}, 72^{\circ} \mathrm{C} 40 \mathrm{~s} \text {, for } 33 \mathrm{cycles}\right) \\
72^{\circ} \mathrm{C} 5 \mathrm{~min} \text { for } 1 \text { cycle }\end{array}$ \\
\hline $\mathrm{G} \beta$-like & $\begin{array}{l}\text { Forward } \\
\text { Reverse } \\
\text { Reverse } \\
\text { (Mutant) }\end{array}$ & $\begin{array}{l}\text { 5'-GATTGGAACCTGGCTACTG }(620 \sim 640) \\
\text { 5'-TAGGGCTGAAGCACAGGGCG }(905 \sim 924) \\
\text { 5'-TAGGGCTGAAGCACAGGGCG } \\
\text { TACTGATAACTTCTTGCTTC }(806 \sim 825)\end{array}$ & $\begin{array}{l}304 \\
225\end{array}$ & $\begin{array}{l}94^{\circ} \mathrm{C} 5 \mathrm{~min} \text { for } 1 \mathrm{cycle},\left(94^{\circ} \mathrm{C} 1 \mathrm{~min},\right. \\
\left.50^{\circ} \mathrm{C} 2 \mathrm{~min}, 72^{\circ} \mathrm{C} 40 \mathrm{~s} \text {, for } 30 \mathrm{cycles}\right), \\
72^{\circ} \mathrm{C} 5 \mathrm{~min} \text { for } 1 \text { cycle }\end{array}$ \\
\hline
\end{tabular}


then corrected by the amounts of $\mathrm{G} \beta$-like mRNA transcript, determined by the same method. The VEGF mRNA expression ratio was defined as the amount of VEGF $m R N A$ divided by the amount of $G \beta$-like mRNA.

\section{Statistics}

The presence of VEGF mRNA detected by RTQ RTPCR or QC RT-PCR in lung cancer material and the corresponding healthy tissue was expressed as a frequency (number of positive results in the total number of samples). The correlation between the levels of expression of VEGF mRNA measured by RTQ RT-PCR or by QC RT-PCR was analyzed by linear regression (Glantz, 1992). The percentage of tumor tissue that showed positive VEGF staining was also correlated with the VEGF mRNA expression quantified by RTQ RT-PCR using linear regression. Statistical tests were performed using the software SPSS 8.0 (SPSS Inc., Chicago, Illinois).

\section{References}

Berkman RA, Merril MJ, Reinhold WC, Monacci WT, Saxena A, Clark WC, Robertson JT, Ali IU, and Oldfield EH (1993). Expression of the vascular permeability factor/vascular endothelial growth gene in central nervous system neoplasms. J Clin Invest 91:153-159.

Boocock CA, Charnock-Jones DS, Sharkey AM, Mclaren J, Barker PJ, Wright KA, Twentyman PR, and Smith SK (1995). Expression of vascular endothelial growth factor and its receptors flt an KDR in ovarian carcinoma. J Natl Cancer Inst 87:506-516.

Brown LF, Berse B, Jackman RW, Tognazzi K, Guidi A, Dvorak H, Senger D, Connolly J, and Schnitt S (1995). Expression of vascular permeability factor (vascular endothelial growth factor) and its receptors in breast cancer. Hum Pathol 26:86-91.

Brown LF, Berse B, Jackman RW, Tognazzi K, Manseau EJ, Senger DR, and Dvorak HF (1993). Expression of vascular permeability factor (vascular endothelial growth factor) and its receptors in adenocarcinomas of the gastrointestinal tract. Cancer Res 53:4727-4735.

Celi FS, Cohen MM, Antonarakis SE, Werithemer E, Roth J, and Shuldiner AR (1994). Determination of gene dosage by a quantitative adaptation of the polymerase chain reaction ( $g d P C R)$ : rapid detection of deletions and duplications of gene sequences. Genomics 21:304-310.

Celi FS, Zenilman ME, and Shuldiner AR (1993). A rapid and versatile method to synthesize internal standards for competitive PCR. Nucleic Acid Res 21:1047.

Chen CA, Cheng WF, Lee CN, Chen TM, Kung CC, Hsieh FJ, and Hsieh CY (1999). Serum vascular endothelial growth factor in epithelial ovarian neoplasms: Correlation with patient survival. Gynecol Oncol 74:235-4.

Clementi M, Menzo S, Bagnarelli P, and Manzin A (1993). Quantitative PCR and RT-PCR in virology. PCR Methods Appl 2:191-196.
Doldrini L, Calcinal A, Silverstri V, Basolo F, Lucchi M, Mussi A, Angeletti CA, Bevilacqua G, and Fontanini G (1999). Quantitation by competitive PCR assay of vascular endothelial growth factor in non-small cell lung carcinoma. Int J Oncol 14:161-8.

Dong G, Yu M, and Smith HS (1993). An improved method of competitive PCR for quantitation of gene copy number. Nucleic Acids Res 21:4848-4849.

Dvorak HF, Brown LF, Dermar M, and Dvorak AM (1995). Vascular permeability factor/vascular endothelial growth factor, microvascular hyperpermeability, and angiogenesis. Am J Pathol 146:1029-1039.

Ferre F (1992). Quantitative or semi-quantitative PCR: Reality versus myth. PCR Methods Appl 2:1-9.

Fink L, Seeger W, Ermert L, Hanze J, Stahl FG, Kummer W, and Bohle R (1998). Real-time quantitative RT-PCR after laser-assisted cell picking. Nat Med 4:1329-1333.

Folkman J, Merler E, Anbemathy C, and Williams G (1971). Isolation of a tumor factor responsive for angiogenesis. J Exp Med 33:275-278.

Fontanini G, Vignati S, Boldrini L, Chine S, Silvestri V, Lucchi M, Mussi A, Angeletti CA, and Bevilacqua G (1997). Vascular endothelial growth factor is associated with neovascularization and influences progression of NSCLC. Clin Cancer Res 3:861-865.

Gibson UEM, Heid CA, and Willian PM (1996). A novel method for real-time quantitative RT-PCR. Genome Res 6:995-1001.

Glantz SA (1992). Alternatives to analysis of variance and the $t$ test based on ranks. In: Glantz SA, editor. Primer of biostatistics, 3rd ed. New York: McGraw-Hill Corporation, 320-371.

Gu JW, Brady AL, Anand V, Moore MC, Kelly WC, and Adair TH (1999). Adenosine upregulates VEGF expression in cultured myocardial vascular smooth muscle cells. Am J Physiol 277:H595-602.

Heid CA, Stevens J, Livak K, and Williams PM (1996). Real time quantitative PCR. Genome Res 6:986-994.

Holland PM, Abramson RD, Watson R, and Gelfand DH (1991). Detection of specific polymerase chain reaction product by utilizing the $5^{\prime}$ to $3^{\prime}$ exonuclease activity of Thermus aquaicus DNA polymerase. Proc Natl Acad Sci USA 88: 7276-7280.

Horak ER, Leek R, Klenk N, Le Jeune S, Smith K, and Stuart $N$ (1992). Angiogenesis assessed by platelet/endothelial cell adhesion molecule antibodies as indicator of node metastases and survival in breast cancer. Lancet 340:1120-1124.

Ivan $\mathrm{B}$, Olivi $\mathrm{M}$, Champeme $\mathrm{H}$, Vidaud $\mathrm{D}$, Liderea $\mathrm{R}$, and Vindaud M (1998). Novel approach to quantitative polymerase chain reaction using real-time detection: Application to the detection of gene amplification in breast cancer. Int $\mathrm{J}$ Cancer 78:661-666.

Kellogg, DE, Sninsky JJ, and Kowk S (1990). Quantitation of HIV-1 proviral DNA relative to cellular DNA by the polymerase chain reaction. Anal Biochem 189:202-208.

Longo N, Berninger NS, and Hartley JL (1990). Use of uracil DNA glycosylase to control carry-over contamination in polymerase chain reaction. Gene 93:125-128. 
Macchiarini P, Fontanini G, Jardin MJ, Squartini F, and Angelerti CA (1992). Relation of neovascularization to metastasis of non-small cell lung cancer. Lancet 340:145-146.

Mountain CF (1986). A new international staging system for lung cancer. Chest 89:225s-233s.

Ohta Y, Ehdo Y, Tanaka M., Shimizu J, Oda M, Hayashi Y, Watanabe $Y$, and Sasaki T (1996). Significance of vascular endothelial growth factor messenger RNA expression in primary lung cancer. Clin Cancer Res 2:1414-1416.

Ohta $\mathrm{Y}$, Watanabe $\mathrm{Y}$, Murakami S, Oda M, Hayashi $\mathrm{Y}$, Nonomura A, Endo Y, and Sasaki T (1997). Vascular endothelial growth factor and lymph node metastasis in primary lung cancer. Br J Cancer 76:1041-1045.

Oshika Y, Nakamura M, todunaga T, Fukushima Y, Hatanaka $\mathrm{H}$, Abe $\mathrm{Y}$, Yamazaki H, Kijima H, Tamaoki N, and Ueyama $\mathrm{Y}$ (1994). Expression of cell-associated isoform of vascular endothelial growth factor 189 and its prognostic relevance in non-small cell lung cancer. Int J Oncol 12:541-544.

Piatak M Jr, Saag MS, Yang LC, Clark SJ, Kappes JC, Luk KC, Hahn BH, Shaw GM, and Lifson JD (1993). High levels of HIV-1 in plasma during all stages of infection determined by competitive PCR. Science 259:1749-1754.

Raeymaekers $L$ (1995). A commentary on the practical application of competitive PCR. Genome Res 5:91-94.

Schor AM and Schor SC (1983). Tumor angiogenesis. J Pathol 41:385-413.

Srivasta A, Laidler P, and Pavies RP (1988). The prognostic significance of tumor vascularity in intermediate thickness skin melanoma: A quantitative histologic study. Am J Pathol 133:419-423.

Suzuki K, Hayashi N, Miyamoto Y, Yamamoto M, Ohkawa K, Ito $Y$, and Sasaki $Y$ (1996). Expression of vascular permeability factor/vascular endothelial growth factor in human hepatocellular carcinoma. Cancer Res 56:3004-3009.

Takahashi Y, Kitadai Y, Bucana CD, Cleary RK, and Ellis LM (1995). Expression of vascular endothelial growth factor and its receptor, KDR, correlates with vascularity, metastasis, and proliferation of human colon cancer. Cancer Res 55: 3964-3968.
Tokunaga T, Oshika Y, Oseki Y, Sadahiro S, Kijima H, Tsuchida T, Yamazaki H, Ueyama Y, Tamaoki N, and Nakamura M (1998). Vascular endothelial growth factor (VEGF) mRNA isoform expression pattern is correlated with liver metastasis and poor prognosis in colon cancer. Brit $\mathrm{J}$ Cancer 77:998-1002.

Viglietto G, Romane A, Maglione D, Rambaldi M, Paolem I, Lago CT, Califano D, Monaco C, Mineo A, Santelli G, and Manzo G (1996). Neovascularization in human germ cell tumors correlates with a marked increase in the expression of the vascular endothelial growth factor but not the placentaderived growth factor. Oncogene 13:577-587.

Volm M, Koomangi R, and Mattern J (1997). Prognostic value of vascular endothelial growth factor and its receptor Flt-1 in squamous cell lung cancer. Int J Cancer 64:64-68.

Weidner N, Semple JP, Welch WR, and Folkman J (1991). Tumor angiogenesis and metastasis: Correlation in invasive breast carcinoma. N Engl J Med 324:1-8.

Weiner N (1995). Intratumor microvessel density as a prognostic factor in cancer. Am J Pathol 147:9-19.

WHO (1982). The World Health Organization histological typing of lung tumours. Am J Clin Pathol 77:123-136.

Yu CJ, She JY, Shun CT, Lin HT, Kuo SH, Luh KT, and Yang PC (1998). Quantitative analysis of mRNA encoding MUC1, MUC2, and MUC5AC: A correlation between specific mucin gene expression and sialomucin expression in non-small cell lung cancer. Am J Respir Cell Mol Biol 18:643-652.

Yuan A, Yang PC, Yu CJ, Lee YC, Yao YT, Chen CL, Lee LN, Kuo SH, and Luh KT (1995). Tumor angiogensis correlates with histologic type and metastasis in non-small cell lung cancer. Am J Respir Crit Care Med 152:2157-2162. 